\title{
Justificativas e motivações do consumo e não consumo de café
}

\author{
Coffee consumption and non-consumption justifications and motivations
}

\author{
Aline Cristina ARRUDA ${ }^{1}$, Valéria Paula Rodrigues MINIM ${ }^{1 *}$, Marco Aurélio Marques FERREIRA², \\ Luis Antonio MINIM ${ }^{1}$, Neuza Maria da SILVA ${ }^{3}$, Claúdio Furtado SOARES ${ }^{4}$
}

\section{Resumo}

O estudo do perfil dos consumidores e dos fatores envolvidos no processo de compra do café é uma ferramenta importante na identificação dos diferentes segmentos deste mercado e de suas potencialidades. Por outro lado, também é importante compreender porque alguns consumidores recusam a bebida. Portanto, objetivou-se neste trabalho entrevistar os moradores da cidade de Belo Horizonte - MG, a fim de identificar consumidores e não consumidores de café, para traçar o perfil de ambos, descrever suas características, fatores motivacionais e justificativas para consumo ou não do café. Para isto, 250 consumidores foram entrevistados e os resultados avaliados de forma descritiva. Os resultados revelaram que a bebida é consumida por uma parcela heterogênea e que corresponde à maioria da população. Em geral, os consumidores associam o consumo do café ao hábito, prazer, família, amizade e trabalho. Isso indica as motivações para o seu consumo reflete o significado social da bebida quer no âmbito doméstico, trabalho ou no círculo de amizade e que este significado está fortemente associado aos hábitos e costumes da sociedade brasileira. Observou-se a necessidade de expansão deste mercado entre os jovens.

Palavras-chave: café; consumidor; não consumidor; mercado; motivação.

\begin{abstract}
The study of consumer's profile and the factors involved in the process of coffee purchase is an important tool in the identification of the different segments of this market and its potentialities. On the other hand, it is also important to understand the reasons why some consumers refuse the drink. Therefore, the aim of this study was to interview the residents of the city of Belo Horizonte - MG - Brazil in order to identify consumers and non consumers of coffee to trace the profile of both, to describe their characteristics, motivational factors and justifications to consume coffee, or not. For that reason, 250 consumers were interviewed and the results were evaluated in a descriptive way. The results revealed that the drink is consumed by a heterogeneous portion of consumers which corresponds to most of the population. In general, consumers associate the consumption of coffee to habit, pleasure, family, friendship, and work. This indicates the motivations for the consumption of coffee, and it reflects the social meaning of the drink in the domestic environment, work or in friendship circles. This meaning is strongly associated with habits of the Brazilian society. The need of expansion of this market among youths was observed.

Keywords: coffee; consumption; non-consumption; market; motivations.
\end{abstract}

\section{Introdução}

Mundialmente, o café é uma das bebidas mais consumidas. No Brasil, o consumo de café também se destaca entre as demais bebidas. Segundo dados da Associação Brasileira da Indústria de Café - ABIC, o mercado brasileiro representa $14 \%$ da demanda mundial, com um consumo de 4,27 $\mathrm{kg}$ de café torrado por habitante/ano, ou seja, quase $70 \mathrm{~L}$ para cada brasileiro (ABIC, 2007).

Vale ressaltar que, atualmente, o consumo de café tem sido incentivado por especialistas da área de saúde. Programas de incentivo ao café baseados em pesquisas e opiniões de especialistas da área de saúde contribuem para desmistificar antigos tabus que relacionavam o café e a cafeína com alterações maléficas para o organismo. Estudos realizados por Almeida et al. (2003) concluíram que o consumo de café e cafeína não deve ser considerado um fator de risco para várias doenças, entre elas, doenças cardiovasculares, câncer de bexiga, de pâncreas e de intestino. A pesquisa indicou que o café é um agente redutor do risco de alguns tipos de câncer devido a substâncias antioxidantes, anticarcinogênicas e antiteratogênicas naturalmente presentes no café ou formadas durante o seu processamento. Segundo Lima (2007), o consumo em quantidades moderadas, de em média até quatro xícaras por dia, torna o cérebro mais atento e capaz de suas atividades intelectuais, diminui a incidência de apatia e depressão e

Recebido para publicação em 6/12/2007

Aceito para publicação em 3/1/2009 (003075)

1 Análise Sensorial de Alimentos, Departamento de Tecnologia de Alimentos, Universidade Federal de Viçosa - UFV, Avenida Peter Henry Rolfs, s/n, Campus Universitário,

Viçosa-MG, CEP36570-000,Brasil,E-mails: acarruda@vicosa.ufv.br;vprm@ufv.br; Iminim@ufv.br

2 Administração Pública e Gestão Social, Departamento de Administração, Universidade Federal de Viçosa - UFV, Avenida Peter Henry Rolfs, s/n, Campus Universitário,

Viçosa-MG, CEP 36570-000, Brasil,,e-mail: marcoaurelio@ufv.br

${ }^{3}$ Ecossistema Familiar, Políticas Públicas, Desenvolvimento Humano e Social, Departamento de Economia Doméstica, Universidade Federal de Viçosa - UFV, Avenida Peter Henry Rolfs, s/n, Campus Universitário,Viçosa - MG, CEP 36570-000,Brasil,e-mail:neuzams@ufv.br

${ }^{4}$ Economia Internacional e Agrícola Departamento de Tecnologia de Alimentos, Universidade Federal de Viçosa - UFV, Avenida Peter Henry Rolfs, s/n, Campus Universitário, Viçosa-MG, CEP 36570-000, Brasil, e-mail: cfurtado@ufv.br

${ }^{*}$ A quem a correspondência deve ser enviada 
estimula a memória, atenção e concentração e, portanto, melhora a atividade intelectual, sendo adequado para todas as idades, inclusive crianças e adolescentes.

Tradicionalmente, os procedimentos para avaliar comercialmente a qualidade do café são baseados, principalmente, no aspecto físico e na "prova de xícara”. Contudo, as características intrínsecas e preferências do consumidor brasileiro em relação à bebida café são pouco conhecidas (MONTEIRO, 2002). Este cenário tem sido modificado na medida em que as indústrias e órgãos relacionados à produção e processamento do café se mostram mais atentos ao comportamento e exigências do consumidor. $\mathrm{O}$ aumento de estudos na área e de pesquisas realizadas junto aos consumidores brasileiros demonstra tal preocupação.

Estudo realizado a pedido da ABIC em 1997, revelou que o café era consumido para reanimar, era bom para consumir no trabalho e para oferecer às visitas em situações sociais, sendo consumido por força do hábito, por prazer e em decorrência do seu sabor. A mesma pesquisa, realizada no ano de 2006, mostrou que o consumo de café continuava associado ao hábito e que o sabor e o aroma eram também incentivadores do consume (ABIC, 2006). Ser considerado um sinalizador social com capacidade de reunir as pessoas além de esquentar e estimular, mostrando forte associação ao dinamismo, foram as conotações mais representativas na pesquisa.

Pesquisa semelhante, realizada por Zylbersztajn, Farina e Santos (1993), concluiu que o café faz parte do cotidiano das pessoas, constituindo-se em produto insubstituível que não sofre concorrência direta de nenhum outro produto. Entretanto, Sette (2000) concluiu em sua pesquisa que os jovens são resistentes ao consumo do café.

Portanto, o modo como ocorre a representação do café para o consumidor é fundamental para a aceitação ou rejeição de um produto e deve ser objeto de estudo para definição de um mercado e elaboração de novos produtos.

Entretanto, a segmentação de mercado para o produto café precisa ser conduzida cuidadosamente, pois o consumidor consome café em diferentes momentos e por diversos motivos. O café reúne uma série de fatores sociais e comportamentais que variam individualmente. Em geral, ele é consumido sob forte impacto social, pois guarda um simbolismo social e ao mesmo tempo cultural e místico.

Neste sentido, o estudo dos motivadores para o consumo de café, por meio do levantamento de perfis e desejos dos consumidores, caracterizando e discriminando segmentos específicos, é uma das etapas para explorar as potencialidades deste mercado, baseado na evidenciação das particularidades de cada grupo.

Assim, diante do amplo e crescente mercado brasileiro para café e da escassez de produtos que perpassem o conceito dos já existentes, cafezinho, expresso e similares, aliado ao conhecimento oriundo da Ciência de Alimentos e aos desejos dos consumidores, este estudo objetivou caracterizar o perfil dos consumidores de café residentes em Belo Horizonte - MG, apresentando suas principais características sócio-demográficas e os fatores motivacionais que influenciam o seu comportamento.
Como forma de complementar o estudo, também avaliou os não consumidores de café para entender as suas justificativas e os substitutos do café. Ressalta-se que este trabalho é parte de um estudo maior sobre comportamento de consumidores de café, com intenção de mapear este mercado, interpretar os desejos dos consumidores e desenvolver novos produtos à base de café. Informamos que a pesquisa passou pelos trâmites necessários para sua realização e foi aprovada inicialmente por uma comissão departamental e, posteriormente, pela comissão de pesquisa da Universidade Federal de Viçosa

\section{Material e métodos}

Foi constituída uma amostra intencional aleatória, estatisticamente significativa, composta por 250 consumidores, residente em Belo Horizonte/MG, entrevistados entre 8 e 11 de maio de 2007. A cidade de Belo Horizonte foi escolhida por suas características sociais e demográficas, visando uma abordagem heterogênea em relação à amostra e assim verificar esta influência no perfil dos seus moradores. As entrevistas foram realizadas no Mercado Central da cidade, situado no Minas Centro, com participantes da Feira de Tricô e Malhas do Sul de Minas e na Serraria Souza Pinto e imediações, por ocasião da Feira Minas Tchê. Os respondentes foram escolhidos aleatoriamente e interrogados por meio de questionários estruturados com questões de caráter exploratório (Tabela 1). As questões foram formuladas com base em estudo anterior (ARRUDA et al., 2007) e outros estudos com consumidores de café (VEGRO et al., 2002; INTERCIENSE, 2006). Um questionário similar foi aplicado àqueles entrevistados que afirmaram não consumir café, com o objetivo de avaliar quais as principais razões e motivações para tal e verificar quais os substitutos do café nestes casos (Tabela 2).

Procedeu-se à avaliação por meio da análise descritiva dos dados. Realizou-se o Teste t para verificar a adequação da quantidade diária consumida e a quantidade recomendada pelos especialistas e a existência de diferença entre a quantidade consumida por homens e mulheres. Os procedimentos operacionais de análise foram realizados com o auxílio do software SPSS $15.0^{\circ}$, em versão licenciada.

\section{Resultados e discussão}

Os resultados revelaram que $83,3 \%$ dos entrevistados são consumidores de café (Figura 1). Este resultado reflete o cenário nacional, mostrando que a porcentagem de pessoas que consome café é significativamente superior à que não consome. Segundo dados da ABIC (2006), 93\% da população brasileira declara que toma café regularmente, e existe uma tendência de crescimento da quantidade consumida. $\mathrm{O}$ consumo no Brasil representa $13 \%$ de todo consumo mundial de café e $51 \%$ dos 31 milhões de sacas/ano, que todos os países produtores de café consomem em conjunto. Estima-se que, no ano de 2007, o mercado interno tenha atingido 17,4 milhões de sacas (ABIC, 2007). As principais justificativas para este aumento estão relacionadas com os esforços do setor cafeeiro em melhoria da qualidade do café produzido, maior percepção e exigências dos consumidores por cafés de qualidade, investimentos em marketing junto aos consumidores e profissionais da área 
médica desmistificando o conceito de que café faz mal à saúde e a consolidação e amadurecimento dos segmentos das cafeterias (MOREIRA, 2007).

Entretanto, o estudo da parcela da população que não consome café é importante para verificar quais são os motivos que influenciam a sua atitude e verificar possíveis lacunas que poderão ser exploradas na identificação de um novo segmento de mercado.

\subsection{Não consumidores de café}

\section{Perfil dos entrevistados}

Do total dos entrevistados, apenas $17 \%$ afirmaram não consumir café e responderam a um questionário com questões específicas para segmento.

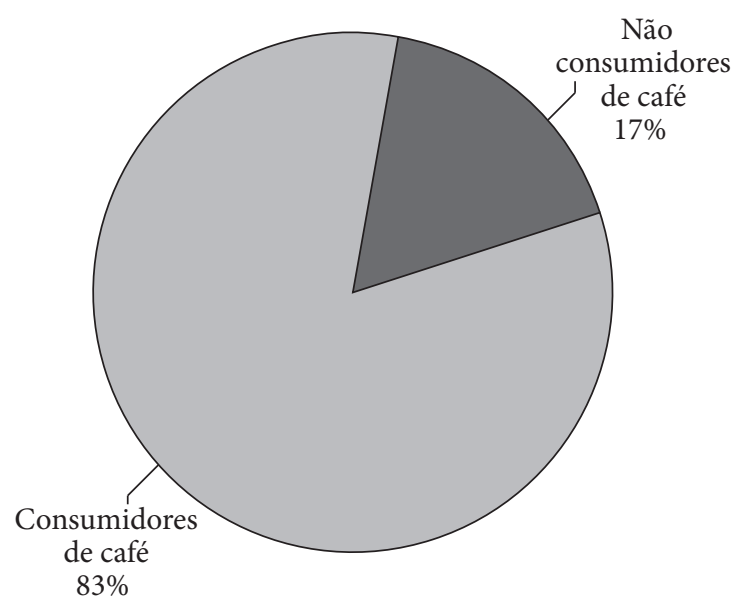

Figura 1. Porcentagem de entrevistados consumidores e não consumidores de café.
Os resultados revelaram a predominância de entrevistados com idade abaixo de 30 anos, demonstrando que os consumidores jovens se mostram mais resistentes ao consumo de café (Figura 2). Este resultado está de acordo com a pesquisa realizada por Arruda et al. (2007), na qual uma pequena parcela de jovens declarou consumir café. Segundo Sette (2000), isto se deve ao fato de que os jovens relacionam o consumo da bebida com hábitos ultrapassados. Nesta pesquisa com 425 universitários com idade entre 18 e 23 anos, o autor concluiu que $50 \%$ deles não o bebiam, demonstrando uma atitude de aversão, considerando-o um produto para pessoas mais velhas; ligado a um clima de vício e cigarro; hábito adquirido frequentemente ao iniciar a vida profissional e relacionado à vida estressante e nervosa, ambientes competitivos e agressivos; antítese do prazer e saúde. Este panorama demonstra a necessidade de posicionamento desse produto entre os mais jovens, exemplificando um mercado a ser explorado. É preciso investir e incentivar o desenvolvimento de novos produtos à base de café, nos quais ele se apresente mais diluído, mais suave e mais doce, com novos sistemas de distribuição e mais serviços que atendam às necessidades e desejos deste consumidor, além disso, o café precisa ocupar mais espaço nos meios de comunicação com mensagens modernas e com linguagem adequada ao público jovem (SETTE, 2000).

Em relação à ocupação profissional, entre os entrevistados observaram-se, em maior número, estudantes, autônomos e funcionários da empresa privada (Figura 3). O alto percentual de estudantes relaciona-se com a faixa de idade predominante e, portanto, reflete o perfil comentado acima.

\section{Aspectos relacionados ao não consumo}

Os entrevistados apontaram como o principal motivo para não consumir café o fato de não apreciarem o seu sabor (Figura 4). Em geral, a avaliação negativa do sabor está relacionada ao gosto amargo demasiado de alguns cafés, geralmente ocasionado pela

Tabela 1. Resumo das questões apresentadas aos consumidores de café.

\begin{tabular}{|c|c|}
\hline \multicolumn{2}{|c|}{ Conteúdo das questões } \\
\hline I e II parte* & III parte ${ }^{* *}$ \\
\hline Sexo, idade, estado civil, grau de instrução, ocupação, renda & Consumo por hábito \\
\hline Qual a bebida mais consumida? & Consumo no término das refeições \\
\hline Quantas xícaras consome por dia? & Consumo por prazer \\
\hline Qual tipo de café consumido? & Consumo para esquentar \\
\hline Qual o local onde mais consome café? & Consumo para relaxar \\
\hline Qual o horário de maior consumo de café? & Consumo no intervalo do trabalho ou estudo \\
\hline Quais atributos observa na compra? & Consumo em casa \\
\hline Possibilidade de compra de novo produto. & Consumo para interagir com amigos \\
\hline Com quais elementos relaciona o consumo de café? & Consumo para descontrair com amigos \\
\hline Possibilidade de consumo de uma bebida com características funcionais & Consumo para ter disposição para trabalho ou estudo \\
\hline \multirow[t]{3}{*}{ Características no café que não gosta } & Acredito que o café reúne as pessoas \\
\hline & Acredito que o café faz mal à saúde \\
\hline & Associo o café com o ato de fumar \\
\hline
\end{tabular}

${ }^{\star}$ Questões fechadas com respostas de acordo com cada pergunta

** Afirmativas avaliadas em uma escala de 1 (concordo fortemente) a 5 (discordo fortemente) 
Arruda et al.

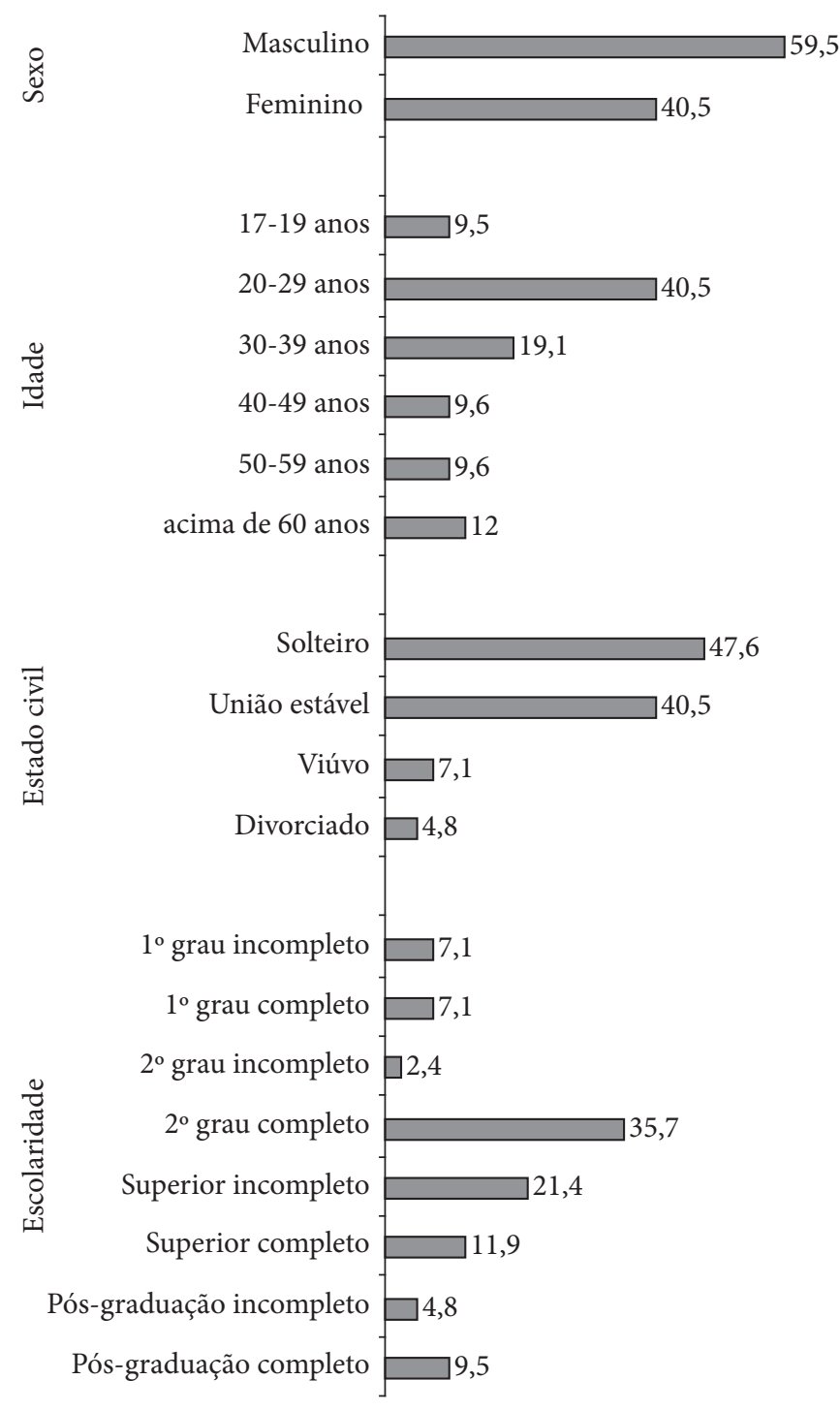

Figura 2. Perfil dos não consumidores de café residentes em Belo Horizonte/MG, expresso em porcentagem.

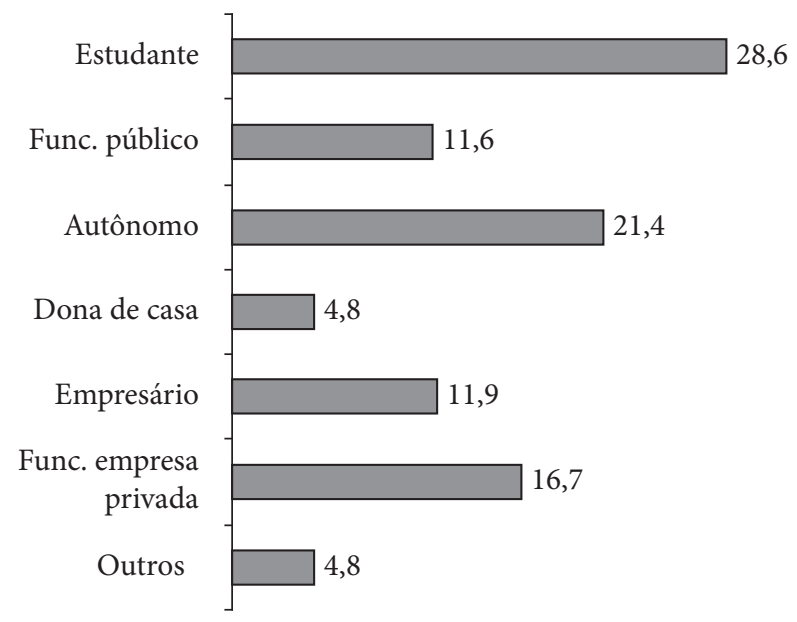

Figura 3. Ocupação profissional dos não consumidores de café residentes em Belo Horizonte - MG, expresso em porcentagem.

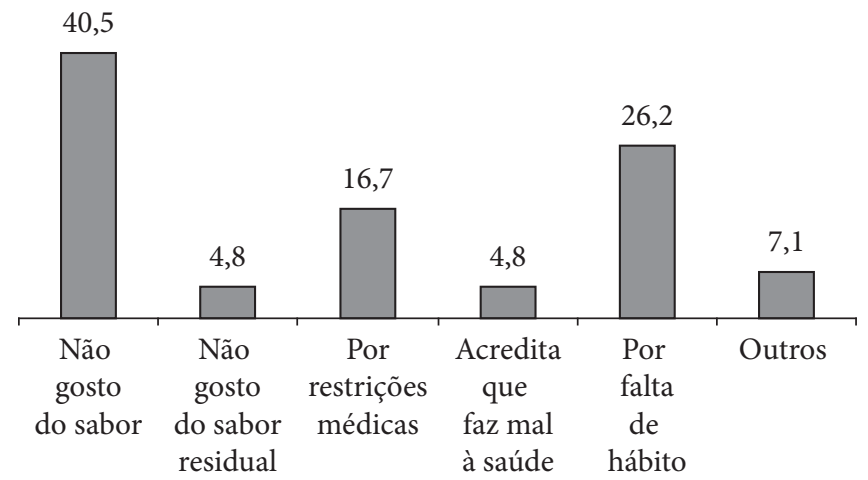

Figura 4. Principais motivos para o não consumo do café, expresso em porcentagem.

Tabela 2. Resumo das questões apresentadas aos não consumidores de café.

\begin{tabular}{l}
\hline \multicolumn{1}{c}{ Conteúdo das questões ${ }^{*}$} \\
\hline Sexo, idade, estado civil, grau de instrução, ocupação. \\
Motivo para não consumir. \\
Substituinte do café. \\
Atributo isolado do café que aprecia. \\
Possibilidade de consumo de uma bebida com características funcionais. \\
Modificações sugeridas no produto. \\
${ }^{*}$ Questões fechadas com respostas de acordo com cada pergunta.
\end{tabular}

má qualidade do pó. Neste sentido, o esforço dos produtores e da indústria em colocar cafés de qualidade no mercado pode contribuir para modificar a percepção do consumidor quanto ao sabor do café.

O número de entrevistados que não consomem café por falta de hábito também é grande (26,2\%). É importante ressaltar que, para este grupo, não há características negativas no café que contribuem para não consumi-lo, apenas não o fazem porque o café não está incluído na sua rotina ou porque foram acostumados assim, repetindo um comportamento aprendido. Os resultados da tabulação cruzada entre as variáveis idade e motivos para não consumir café revelam que a faixa etária entre 20 e 29 anos relaciona o não consumo de café a seus hábitos, indicando a necessidade de explorar este mercado por meio de incentivos que motivem o consumidor jovem a consumir café.

Ressalta-se a significativa porcentagem dos que não consomem café por restrições médicas (16,7\%). A maioria dos entrevistados atribuiu ao café a ação de maximizar os sintomas dos problemas gástricos e o relataram como principal causador de azia e úlceras, sendo, portanto, não recomendado pelos seus médicos. Entretanto, pesquisas realizadas anualmente demonstram que a recomendação médica no sentido de não consumir café está diminuindo (INTERCIENSE, 2006), 
provavelmente como reflexo das inúmeras campanhas de incentivo ao consumo de café, que incluem a distribuição de boletins e informativos entre os profissionais de saúde e apoio de grandes instituições de pesquisa hospitalar, contribuindo para dar credibilidade ao programa. Ao mesmo tempo, os benefícios do café para a saúde são ressaltados por meio de pesquisas que comprovam que o consumo de café é um agente redutor do risco de alguns tipos de câncer devido a substâncias antioxidantes, anticarcinogênicas e antiteratogênicas naturalmente presentes no café ou formadas durante o seu processamento, além de estimular a memória, a atenção e a concentração (ALMEIDA et al., 2003; LIMA, 2007).

Em relação às bebidas que substituem o café, os consumidores apontaram os chás, sucos e leite como principais substitutos (Figura 5).

Observou-se que, geralmente, os consumidores adicionam o leite, chocolate, achocolatados, ou similares e os utilizam no café da manhã e/ou no lanche da tarde para substituir o café. $\mathrm{O}$ uso destes produtos como substitutos do café sugere

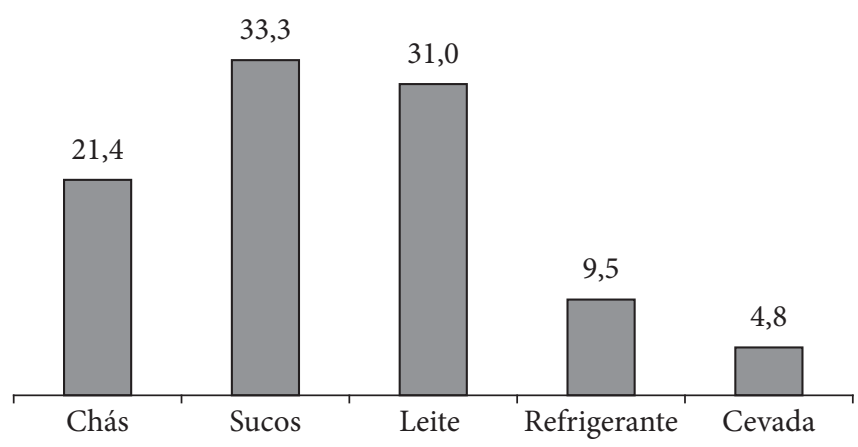

Figura 5. Produtos utilizados pelos consumidores como substitutos do café, expressos em porcentagem.

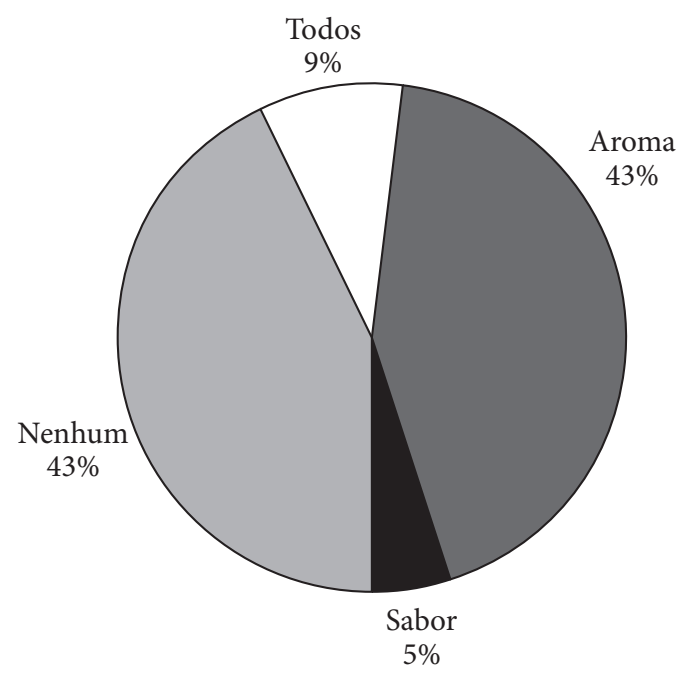

Figura 6. Atributos apreciados isoladamente pelos não consumidores de café. a possibilidade de usá-los como base na criação de um novo produto à base de café, agregando as qualidades apreciadas pelo consumidor às características do café, no desafio de conquistar novos mercados, ou seja, juntar em um mesmo produto o café e um dos produtos apreciados pelos entrevistados.

Embora, estes entrevistados não façam uso do café, existem atributos isolados do produto que são apreciados (Figura 6).

Observa-se que o aroma é o atributo que os entrevistados mais gostam no café, mesmo quando não o consomem. O aroma do café é decorrência da presença de compostos voláteis, sendo encontrados principalmente na forma de aldeídos, cetonas e ésteres metílicos. Nos frutos verdes estes compostos apresentam valores sensoriais bastantes baixos e, no decorrer da maturação, ocorre um aumento gradativo que contribui para o aroma do café e torna-se responsável pelo sabor final do produto (PIMENTA, 2003). As indústrias cosméticas e de alimentos já se atentaram para este fato e têm desenvolvido produtos aromatizados com essências de café.

Uma pequena porcentagem dos entrevistados (9\%) afirmou gostar de todos os atributos do café e só não fazem uso dele por restrições médicas, conforme discutido anteriormente.

Quando questionados sobre a possibilidade de consumo de um produto á base de café com características funcionais, $42,9 \%$ dos entrevistados afirmaram que estariam dispostos a comprálo, enquanto $16,7 \%$ responderam que talvez comprariam. Desta forma, nota-se mais uma vez, que existe possibilidade de explorar o mercado dos não consumidores de café por meio de inovações da indústria de alimentos. A junção do interesse em produtos com apelos funcionais e os produtos que mais apreciam como leite e refrigerante pode resultar em um novo produto com alto potencial de mercado.

\subsection{Consumidores de café}

\section{Perfil dos consumidores}

As principais características dos consumidores de café residentes em Belo Horizonte - MG são homens e mulheres com idade variando entre 15 e 75 anos, com média de 41 anos e desvio padrão de 15,4 anos (Figura 7).

Em relação ao nível de escolaridade, 75,7\% dos entrevistados possuem no mínimo o segundo grau completo. Deste percentual, $34,7 \%$ cursaram ou cursam o ensino superior, demonstrando que o consumo de café não está relacionado com o grau de escolaridade. Acredita-se em uma relação entre a renda, o tipo de café e a forma de preparar a bebida, já que o aumento da renda, o que geralmente ocorre concomitante ao aumento do grau de escolaridade, proporciona maior disponibilidade para pagar por produtos diferenciados (FRENCH; BOOTH, 1994; SOLOMON, 2002).

As ocupações dos entrevistados são variadas (Figura 8), demonstrando que a técnica de amostragem foi eficaz para selecionar uma amostra heterogênea. Devido à impossibilidade de coletar dados referentes à renda da amostra, a distribuição das ocupações foi utilizada como parâmetro para inferir sobre a renda da população, estimando-se uma variação média de 


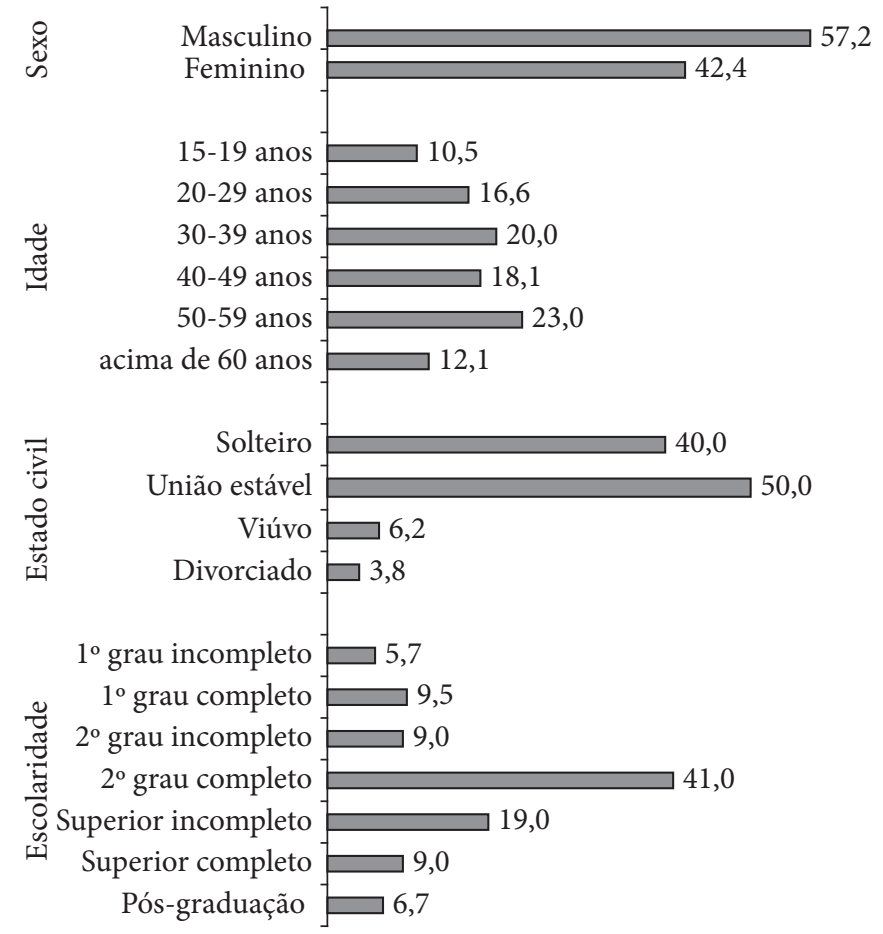

Figura 7. Perfil dos consumidores de café residentes em Belo Horizonte/ MG, expresso em porcentagem.

renda familiar em torno de $\mathrm{R} \$ 1.500,00$, já que pelas profissões listadas, a renda salarial variou de 1 a 30 salários mínimos, após a exclusão de alguns que seriam considerados discrepantes.

\section{Comportamento de consumo}

A Figura 9 permite avaliar as preferências do consumidor por bebidas e verificar quais são os concorrentes do café.

O café é citado por $23,3 \%$ dos entrevistados como a bebida mais consumida e, portanto, ocupa posição de destaque na preferência dos consumidores. Observa-se que ele também é apontado como a segunda bebida mais consumida $(25,2 \%)$ e ocupa a segunda posição quando se refere à terceira bebida mais consumida. De forma semelhante aos hábitos dos não consumidores de café, os sucos, iogurtes, leite e refrigerantes possuem uma significativa participação no consumo e preferência deste grupo, fazendo necessário, portanto, monitorar o crescimento dessas bebidas como concorrentes e substitutos do café. Por outro lado, a combinação destes produtos com café, para criar uma nova bebida, pode gerar novas oportunidades de investimentos, adicionando-se ao produto original o sabor diferenciado e as características do café, possibilitando atender dois segmentos de mercado diferenciados, por meio de um só produto. Desta forma, agrega-se valor ao produto final, já que este proporcionaria ao consumidor as vantagens de obter de uma só vez os benefícios e características de dois produtos, além de estender o mercado aos jovens, interessados em consumir um produto diferenciado (SETTE, 2000).

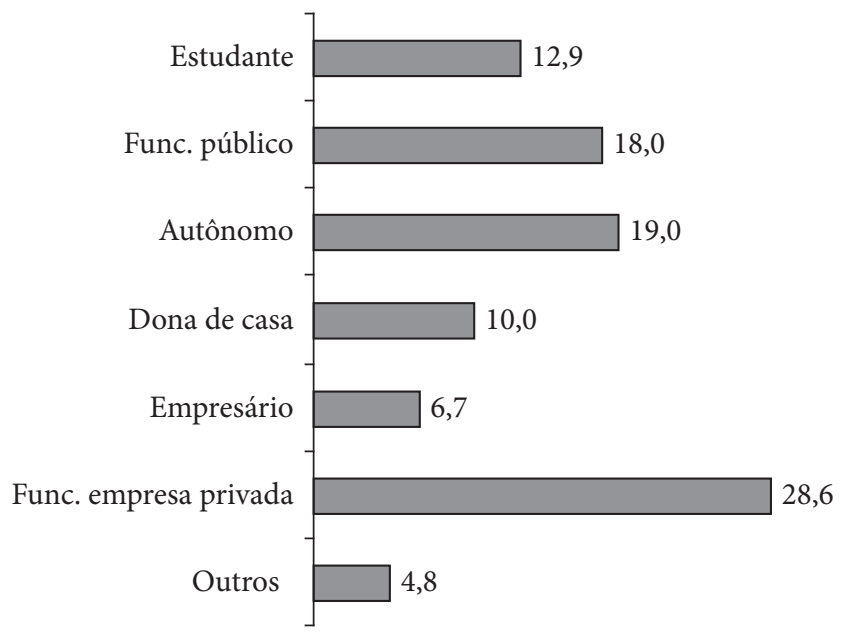

Figura 8. Ocupação profissional dos consumidores de café residentes em Belo Horizonte - MG, expressa em porcentagem.

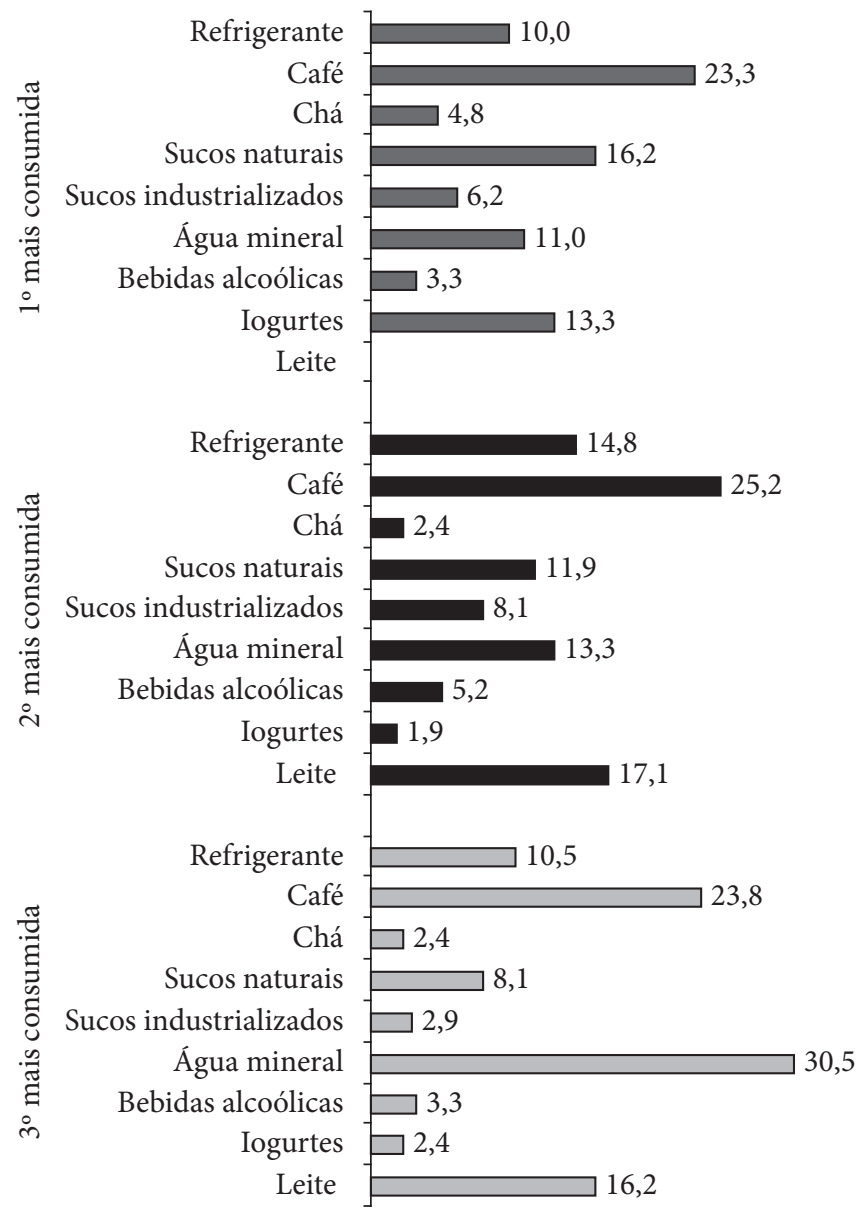

Figura 9. Bebidas ordenadas de acordo com a preferência de consumo. Cada consumidor listou as três bebidas mais consumidas e preferidas. 
Entretanto, a avaliação das respostas dos entrevistados quanto ao consumo de um novo produto, mostrou que ainda existe uma pequena parcela da população $(6,7 \%)$ que resiste a inovações relacionadas ao café e afirmaram que não comprariam nenhum outro produto além do café tradicional (Figura 10). Dentre os que apontaram algum produto, 33,8\% citaram café preparado e adoçado; $21,4 \%$, café com leite; $11,4 \%$, café em saquinhos; e 9,5\%, mistura de café, leite e chocolate. Outros produtos (sobremesa láctea, energético, iogurte, café gelado e refrigerante) foram citados nesta sequência, porém em menores proporções. Ressalta-se que a falta de conhecimento de produtos diferenciados e a tradição brasileira de tomar o café apenas na forma tradicional, com variações servidas somente em cafeterias, dificultou as respostas dos entrevistados.

A Tabela 3 demonstra os resultados do teste t para verificar a diferença entre o consumo de café por homens e mulheres.

Observou-se que existe diferença significativa $(\mathrm{p}<0,05)$, entre a quantidade de café diária consumida por homens e mulheres. $\mathrm{O}$ consumo entre os homens é maior, apresentando

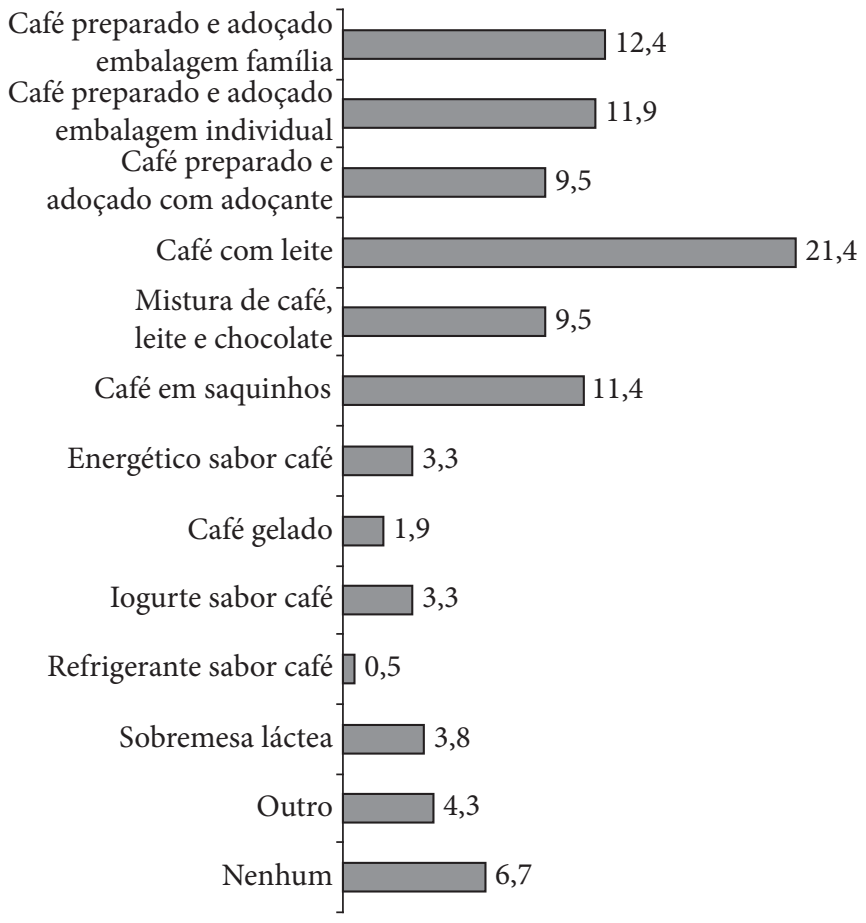

Figura 10. Possibilidade de consumo de novos produtos à base de café, expressa em porcentagem.

Tabela 3. Resultado do teste t para quantidade de café consumido entre homens e mulheres.

\begin{tabular}{cccccc}
\hline Quantidade & Sexo & Média & Desvio padrão & $\mathrm{t}$ & Sig. \\
\cline { 2 - 6 } diária & Masculino & 4,2 & 2,8 & 2,1 & $0,37^{*}$ \\
& Feminino & 3,4 & 2,5 & & \\
\hline
\end{tabular}

*Significativo a $5 \%$ de probabilidade. média de 4,2 xícaras, com desvio padrão de 2,8 , em comparação com o das mulheres, em que a média é de 3,4 , com desvio padrão de 2,5 xícaras diárias.

A análise da quantidade diária consumida demonstrou que não houve diferença significativa $(p>0,05)$ entre o consumo médio da amostra $(3,75)$ e a quantidade recomendada pelos especialistas. Segundo Lima (2007), o consumo de até quatro xícaras por dia é adequado para todas as idades, inclusive crianças e adolescentes.

O tipo de café consumido é predominantemente coado e filtrado (91\%), proveniente de pó tradicional (Figura 11).

Dados da ABIC (2006) revelaram que, em 2005, 96\% do café consumido no Brasil, foi do tipo convencional torrado e moído, ainda que tivesse havido o aumento do consumo dos tipos orgânico (0,5\%) e descafeinado (1\%), em comparação com os dois anos anteriores. Vegro et al. (2002) e Arruda et al. (2007) também constataram este comportamento em pesquisas semelhantes. A aceitação de cafés do tipo descafeinado e orgânico entre os consumidores de Viçosa - MG foi avaliada por Arruda et al. (2006) e concluíram que, ainda que o termo orgânico e descafeinado remetam a produtos mais saudáveis, estes tiveram baixa aceitação junto aos consumidores, provavelmente devido à falta de familiarização com estes

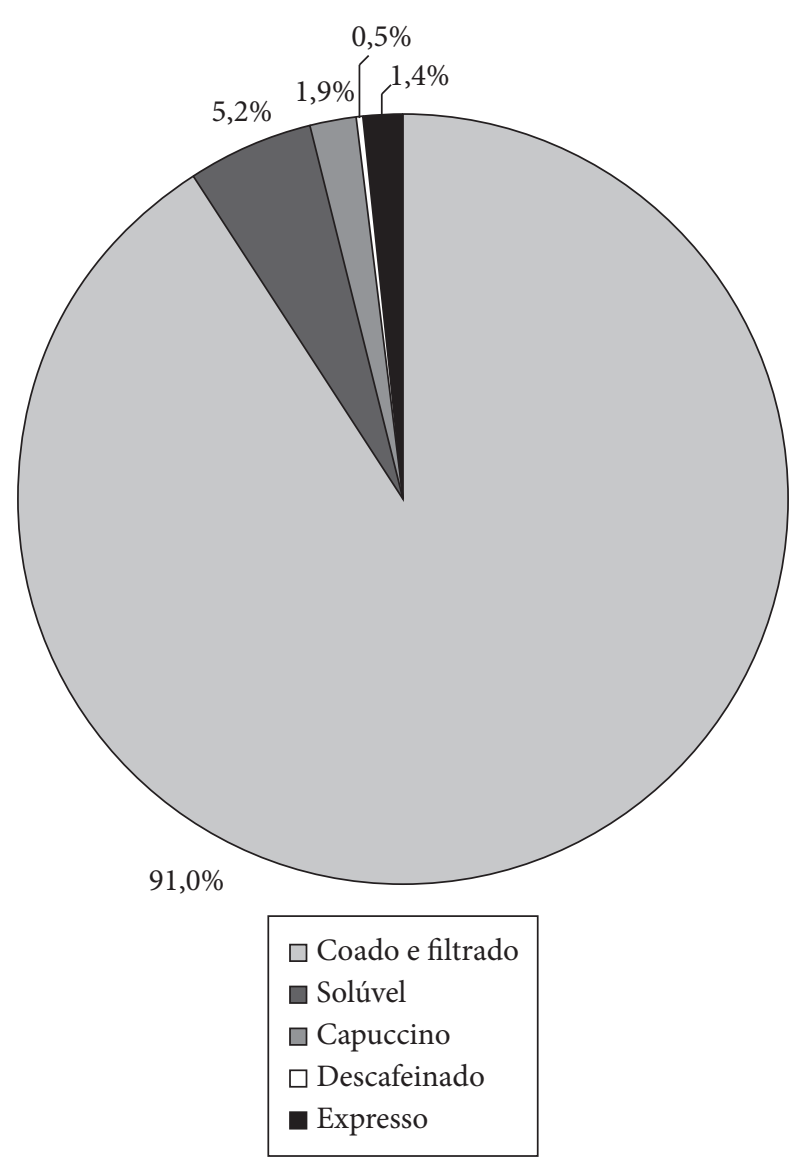

Figura 11. T ipo de café consumido pelos entrevistados. 
produtos. Entretanto, o pequeno percentual registrado dos cafés do tipo solúvel, expresso, capuccino e descafeinado (9\%) e a não ocorrência do tipo orgânico surpreenderam a equipe, pois havia suposições de que, como se tratava de uma grande cidade, a divulgação e o consumo destes produtos seriam maiores. Outra razão para acreditar no consumo de café orgânico era a preocupação com o meio ambiente, grandemente divulgada nos dias de hoje, assumindo um caráter de filosofia de vida para alguns consumidores, que defendem o consumo de produtos sustentáveis e seguros para a saúde de consumidores e produtores (CLARO; CLARO, 2004; PELSMACKER et al., 2005). Ressaltase, portanto, a necessidade de incentivo para expandir este mercado.

O ambiente doméstico foi apontado como o principal local de consumo de café (71\%), seguido de lanchonetes (19\%) e ambientes de trabalho (8,6\%). As cafeterias são o lugar onde menos se consome café, demonstrando que, apesar do significativo crescimento do setor nos últimos anos e o aperfeiçoamento em serviços e produtos de qualidade, este segmento atinge um perfil específico de consumidores, geralmente apreciadores de café de qualidade superior, dispostos a pagar mais pelo produto, pois valorizam o espaço físico do estabelecimento e os serviços de funcionários especializados em servir café.

O café é consumido em maior quantidade no período da manhã $(50,5 \%)$. Trinta e oito por cento afirmaram ter o hábito de fazer uso do produto no café da manhã e 20,5\% estendem este uso até o horário do almoço. Este hábito é justificado pela percepção do produto como estimulante, sendo necessário para "começar bem o dia". O mesmo comportamento não foi percebido no período da tarde $(5,7 \%)$ e significativamente diminuído após o jantar, na intenção de "atrapalhar o sono". Os consumidores que tomam uma quantidade diária maior (acima de cinco xícaras) afirmaram que o fazem durante todo dia (10\%), entretanto estes representam uma pequena parcela da população (10\%).

Em geral, os consumidores não possuem o hábito de tomar café após as refeições, entretanto nota-se que é um produto tradicionalmente presente no café da manhã e lanche da tarde, refletindo os hábitos culturais do brasileiro.

Marca, qualidade, selo de pureza e preço, foram ordenados como atributos mais observados na escolha do produto (Figura 12). Segundo Cobra (2005), os consumidores estão mais educados e mais exigentes em relação ao consumo de café, principalmente em relação á qualidade do produto. Percebeu-se que o selo pureza é percebido como instrumento de validação da qualidade do produto e quando presente, aumenta a credibilidade da marca.

Resultados semelhantes foram encontrados por Arruda et al. (2007), com os consumidores privilegiaram a marca e a qualidade do café. Zylbersztajn, Farina e Santos (1993) constataram que consumidores privilegiaram a qualidade em suas decisões de compra, porém a associavam à confiança na marca, mostrando-se resistentes quanto à possibilidade de substituição da marca conhecida/consumida. De acordo com Kotler e Armstrong (2003), os consumidores aprendem a agir diante das expectativas que têm do produto. Em relação a este aprendizado, verificou-se que na compra do café, quando as expectativas sobre uma determinada marca é atendida de forma positiva, o consumidor ficará satisfeito e permanecerá fiel por um período, que será definido de acordo com sua percepção de qualidade. Em relação ao preço, os resultados demonstram que embora não seja o fator decisivo na escolha do produto, muitos consumidores prezam a combinação entre qualidade e preço.

A combinação ideal entre intensidade do sabor, aroma e doçura do café foi avaliada por meio de escala não estrutura de 9 $\mathrm{cm}$, na qual 1 representa extremante fraco/doce e 9 extremamente forte/doce. Para os entrevistados um café ideal seria resultado da combinação de um sabor equilibrado, tendendo para forte, aroma extremamente forte e doçura equilibrada (Figura 13). Nota-se que o aroma é a característica mais apreciada do café, tanto pelos consumidores quanto pelos não consumidores de café. Portanto, este é um atributo que deve ser explorado pela indústria cafeeira como estratégia de marketing na divulgação e incentivo ao consumo do produto e na formulação de novos produtos. A intensidade da doçura (equilibrada tendendo para fraco), também serve como parâmetro para formulação de novos produtos pois parece seguir uma tendência global. Segundo Nairan et al. (2004), a aceitação de cafés filtrados avaliados por um painel de consumidores, apresentou correlação negativa com maior intensidade do gosto doce. $\mathrm{O}$ autor comenta que dois aspectos podem ser inferidos sobre este comportamento, o primeiro está relacionado ao fato do açúcar prejudicar a apreciação do sabor do café e segunda à preocupação com ingestão de calorias adicionais. De qualquer modo, o fato é que os consumidores preferem café, com menor quantidade de açúcar.

Quando questionados sobre a rejeição de algum atributo do café, $69 \%$ dos entrevistados responderam que não rejeitavam nenhuma característica na bebida. Dos $31 \%$ que responderam afirmativamente, $11 \%$ rejeitam as variações geradas no sabor e aroma provenientes de pó de má qualidade ("gosto de folha seca",

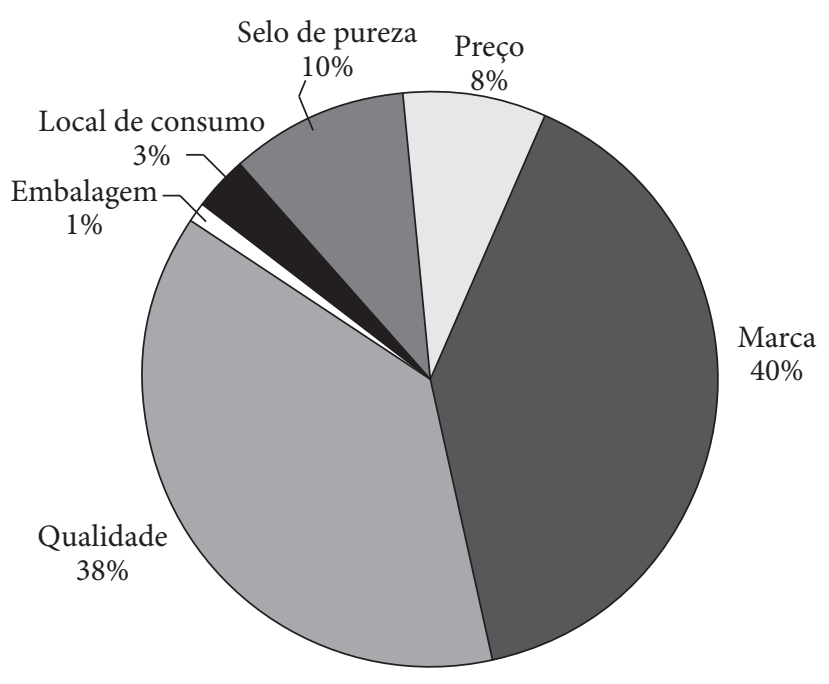

Figura 12. Atributos observados na compra do café. 


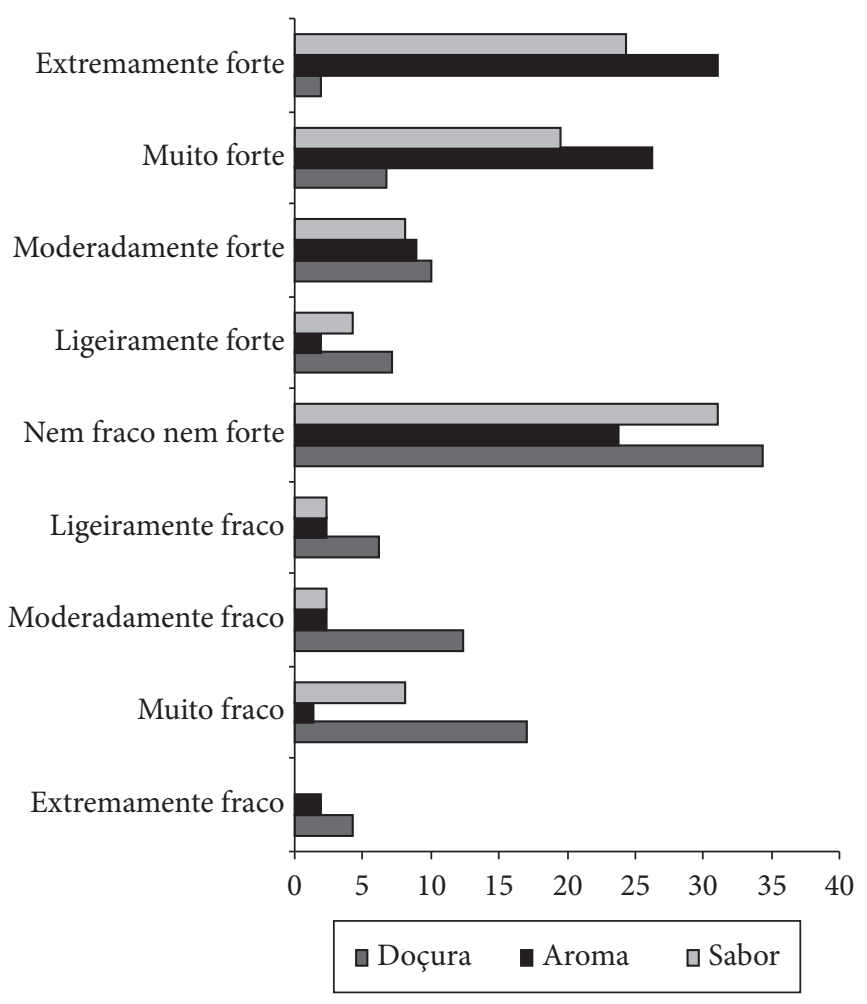

Figura 13. Intensidades do sabor, aroma e doçura ideal para os consumidores de café. *Atributos avaliados em escala não estruturada de nove pontos ( 1 - extremamente fraco e 9 - extremamente forte).

"gosto de mato", "gosto de café verde", "gosto de café fermentado" e "cheiro de inseto"). Este resultado revela que o consumidor está cada vez mais exigente em relação à qualidade do café (COBRA, 2005), e que os esforços aplicados no cultivo, colheita e processamento para um café de melhor qualidade, ocasiona maior satisfação dos consumidores (LOPES, 2000).

Um outro aspecto apontado como negativo é a relação entre café e insônia. De fato, este é um dos efeitos do café quando consumido em doses elevadas, graças à ação estimulante dos seus constituintes químicos no sistema nervoso, principalmente a cafeína (TRUGO, 2003). Neste sentido, a recomendação médica é que o consumo à noite deve ser em pequenas doses ou, em casos de alta sensibilidade à cafeína, deve ser suspenso neste horário (LIMA, 2007). Semelhantemente aos não consumidores de café, problemas de gastrite e azia decorrentes da ingestão de café foram citados, instigando o desenvolvimento de pesquisas que minimizem este efeito.

O café foi associado pela maioria dos consumidores (38,1\%) ao hábito, demonstrando que eles reproduzem o comportamento aprendido com seus antecedentes, revelando a necessidade de incentivos para despertar neles, motivações extras para consumir café. O segundo elemento mais associado ao consumo de café foi prazer, comprovando o grau de afetividade despertado pela bebida, conforme já verificado anteriormente quando foi feita a comparação da preferência pelo café e outros produtos.
È importante evidenciar a associação do café com informações de cunho social, como amizade, convívio social e família, revelando o seu papel como elemento agregador em ambientes diferenciados. A associação do café com trabalho e estudo permite inferir sobre a relação existente entre esses elementos e o seu efeito estimulante, ao mesmo tempo em que possibilita uma pausa nessas atividades. Desta forma, o café é utilizado para satisfazer as necessidades fisiológicas e psicológicas dos consumidores. Semelhantemente, nas pesquisas de Zylbersztajn, Farina e Santos (1993), Luna et al. (2001), Vegro et al. (2002), Deboçã Santos e Rezende (2004), Arruda et al. (2007), Ferreira et al. (2007), o café foi associado a descontinuidades de rotina, tanto em casa como no trabalho; cortesia, apreço para com aqueles que recebemos; e momentos de reflexão.

\section{Conclusões}

O café ocupa posição de destaque entre as bebidas mais consumidas pelos brasileiros e representa um mercado potencialmente grande. O estudo do comportamento dos consumidores de Belo Horizonte/MG em relação às principais motivações para consumir ou não o café revelou que os jovens são os que menos consomem café, e os motivos para não consumi-lo estão relacionados com a desaprovação do sabor, hábitos de consumo e restrições médicas. Os chás, leite e sucos são os substitutos do café e sugerem a possibilidade de usálos como base na criação de um novo produto à base de café, agregando as suas qualidades e preferência do consumidor às características do café, no desafio de conquistar novos mercados. $\mathrm{O}$ aroma do café é o atributo mais apreciado tanto pelos que consomem café, quanto pelos que não o fazem.

Em geral, os consumidores associaram o consumo do café ao hábito, prazer, família, amizade e trabalho. Isso indica que as motivações para o seu consumo refletem o significado social da bebida quer no âmbito doméstico, trabalho ou no círculo de amizade e que este significado está fortemente associado aos hábitos e costumes da sociedade brasileira. O consumo do café transpassa o campo da satisfação das necessidades fisiológicas e envolve também as necessidades psicológicas, como relacionamento, satisfação pessoal e profissional.

\section{Referências bibliográficas}

ASSOCIAÇÃO BRASILEIRA DA INDÚSTRIA DE CAFÉ - ABIC. Consumo de café no Brasil atinge 15,95 milhões de sacas. Jornal do Café, n. 154, p. 10-12, 2006.

ASSOCIAÇÃO BRASILEIRA DA INDÚSTRIA DO CAFÉ - ABIC. Tendências do Consumo de Café no Brasil em 2006. Tendências de consumo IV. Disponível em: http:<//www.abic.com.br/arquivos/ pesquisas/pesq_tendencias_consumo_nov06.pdf $>$.

ASSOCIAÇÃO BRASILEIRA DA INDÚSTRIA DE CAFÉ - ABIC. Estatísticas - indicadores da indústria de café no Brasil. Disponível em: $<$ http://www.abic.com.br/estatisticas.html $>$. Acesso em: Junho 2006.

ASSOCIAÇÃO BRASILEIRA DA INDÚSTRIA DE CAFÉ - ABIC. Estatísticas - indicadores da indústria de café no Brasil. Disponível em: $<$ http://www.abic.com.br/estatisticas.html $>$. Acesso em junho de 2007. 
ALMEIDA, A. A. P. et al. Café e saúde:três décadas de estudos. Revista Brasileira de Armazenamento, edição especial, n. 7, p. 56-63, 2003.

ARRUDA, A. C. et al. Café convencional, orgânico e descafeinado: impacto da informação na aceitação da bebida. Revista Brasileira de Armazenamento, edição especial Café, n. 9, p. 94-99, 2006.

ARRUdA, A. C.; FERREIRA, M. A. M.; MiNiM, V. P. R. Perfil dos consumidores de café de Viçosa/MG: Um estudo exploratório. In: SIMPÓSIO DE PESQUISAS DE CAFÉS DO BRASIL, 5, 2007, Águas de Lindóia.

CLARO, D. P.; CLARO, P. B. O. Coordinating B2B cross-border supply chains: the case of the organic coffee industry executives can be found at the end of this issue. Journal of Business \& Industrial Marketing, v. 19, n. 6, p. 405-414, 2004.

COBRA, M. Administração de marketing. 2 ed. São Paulo: Atlas, 1992. $806 \mathrm{p}$.

COBRA, M. Administração de Marketing no Brasil. 2 ed. São Paulo: Cobra Editora e Marketing, 2005, 451 p.

DEBOÇÃ, L. P.; SANTOS, J. A. dos; REZENDE, A. M. Mercado de café torrado e moído: um estudo de caso. Revista Brasileira de Armazenamento, edição especial Café, n. 8, p. 54-58, 2004.

FERrEIRA, M. A. M.; ARRUDA, A. C.; MINIM, V. P. R. Perfil dos Consumidores de Café de Viçosa/MG: Análise da Motivação como Antecedente do Consumo. In: CONGRESSO DA SOBER, 2007, Porto Alegre.

FRENCH, J. A.; BLAIR, A. J.; BOOTH, D. A Social and emotion state in eating and drinking. Bristish Food Journal, v. 96, n. 1, p. 23-28, 1994.

Interciense Informação e tecnologia. Tendências de consumo IV. Disponível em http:// ww.abic.com.br/arquivos/pesquisas/abic_ pesquisa_consumo_05/jan/06.pdf

KOTLER, P.; ARMSTRONG, G. Princípios de marketing. 9 ed. [S.l.]: Pearson-Prentice Hall, 2003.

LIMA, D. R. Café e composição química. Disponível em: http://www.abic. com.br/café_composiçãoquimica.html. Acesso em: Janeiro 2007.
LOPES, L. M. V. Avaliação da qualidade de grãos de diferentes cultivares de cafeeiro (Coffea arabica L.). Lavras, 2000. Tese (Mestrado em Ciência dos Alimentos) - Universidade Federal de Lavras.

LUNA, R.M.; SETTE, R.S.; VILAS BOAS, L.H. B.; MARIO, T.M.C.; ANTONIALLI, L.M. O perfil dos consumidores de café. In: 270 Congresso Brasileiro de Pesquisas Cafeeiras. Uberaba/MG. Anais, v. 27, p. 159-161, 2001.

MONTEIRO, M. A. M. D. S. Caracterização sensorial da bebida de café (Coffea arabica L.): análise descritiva quantitativa, análise tempo-intensidade e testes afetivos. Viçosa, 2002. Tese (Doutorado em Ciência e Tecnologia de Alimentos) - Universidade Federal de Viçosa.

MOREIRA, M. Mais um café por favor. Jornal do café. n. 157, p. 6-10, 2007.

PELSMACKER, P. de et al. Consumer preferences for the marketing of ethically labelled coffee. International Marketing Review, v. 22, n. 5, p. 512-530, 2005.

PIMENTA, C. J. Qualidade do café. Lavras/MG: Editora UFLA, 2003. $304 \mathrm{p}$.

SETTE, R. de S. Significado do café para jovens brasileiros. In: SIMPÓSIO DE PESQUISA DOS CAFÉS DO BRASIL. Resumos expandidos... Brasília, DF.: Embrapa Café; Belo Horizonte: Minasplan, 2000.

SOLOMON, M. R. Comportamento do consumidor: comprando, possuindo e sendo. 5 ed. Porto Alegre: Bookman, 2002. 445 p.

TRUGO, L. C.; NOGUEIRA, M. Distribuição de isômeros de ácido clorogênico e teores de cafeína e trigonelina em cafés solúveis brasileiros. Ciência e Tecnologia de Alimentos, v. 23, n. 2, p. 296-299, 2003.

VEGRO, C. L. R. et al. O prazer e a excelência de uma xícara de café expresso: um estudo de mercado. São Paulo: Editora Agronômica Ceres Ltda., 2002. 111 p.

ZYLBERSZTAJN, D.; FARINA, E. M. M. Q.; SANTOS, R. O sistema agroindustrial do café. Porto Alegre: Ortiz, 1993. 277 p. 